\title{
The Role of Stress Hormones in Dental Management Behavior Problems
}

\author{
M. DUŠKOVÁ ${ }^{1}$, J. VAŠÁKOVÁ ${ }^{2}$, J. DUŠKOVÁ ${ }^{2}$, J. KAIFEROVÁ ${ }^{2}$, Z. BROUKAL ${ }^{2}$, \\ L. STÁRKA ${ }^{1}$
}

${ }^{1}$ Institute of Endocrinology, Prague, Czech Republic, ${ }^{2}$ Institute of Dental Medicine, First Faculty of Medicine, Charles University, Prague, Czech Republic

Received April 5, 2017

Accepted April 25, 2017

\begin{abstract}
Summary
Dental management behavior problems are thought to be both multifactorial and multidimensional, consisting of physiological, behavioral and cognitive components. The stress response to pain or even the anticipation of distress initiates activation of the hypothalamic-pituitary-adrenal axis and causes an increase of cortisol and catecholamines. The literature on the role of hormones in dental management behavior problems comprises about one hundred papers, which have mainly been focused on this activation of the HPA axis in various situations in dental care. They have generally used salivary cortisol as a marker of the activity of the HPA axis, sometimes combined with salivary alpha amylase. Here we summarize the literature data on the role of stress hormones in dental management behavior problems.
\end{abstract}

\section{Key words}

Phobia • Fear • Anxiety • Dental treatment • Cortisol • Adrenals • Catecholamines

\section{Corresponding author}

M. Dušková, Department of Steroids and Proteofactores, Institute of Endocrinology, Národní 8, 11694 Prague 1, Czech Republic. E-mail: mduskova@endo.cz

\section{Introduction}

"Dental management behavior problems" is the common expression for uncooperative and disruptive behaviors that result in delays of treatment or make treatment impossible. Given the increasing prevalence of behavioral disorders in dental treatment, especially in children (on the European continent 6-22\% of children), this issue has received considerable attention, not only among care providers but also in collaboration with other specialists.

In the literature, dental management behavior problems include the phenomena of fear, anxiety and phobia, each of which has a precise definition referring to specific types of reactions.

Fear is defined as a response to an imaginary or real threat, and is considered an integral part of the adaptive physiological aspects of human development (Rantavuori 2008). Clinically, it is used as a description for the pathological fear response to specific objects. Exposure to these dreaded objects creates four component reactions in the body: cognitive, somatic, emotional, and behavioral (Lang and Cuthberg 1984). Anxiety is very similar to fear, and in a healthy individual at risk it is a physiological and effective phenomenon; however, in other cases it can become a pathological phenomenon. Phobia is an intense fear related to a specific object, which usually leads to the avoidance of this object (Rantavuori 2008). Avoidance of such an intensity that causes significant problems and interferes with the social behavior and status of the individual qualifies these reactions as phobias (Milgrom et al. 1995a). Phobic individuals overestimate the consequences of exposure to feared stimuli, and their responses are disproportionate to the actual risk (Rantavuori 2008).

Dental fear is commonly thought to be multifactorial and multidimensional, consisting of physiological, behavioral and cognitive components 
(Karjalainen et al. 2003, Milsom et al. 2003). Although dental fear is a much studied and prevalent phenomenon, the acquisition and characteristics of dental fear are still not well understood, especially in children. Dental fear has been shown to be acquired mainly in childhood and adolescence (Locker et al. 1999). On the other hand, some children do not acquire dental fear despite painful invasive experiences. These contradictory findings have been one of the major motivations for studying dental fear in children.

The prevalence of dental anxiety has been the subject of many surveys. Studies have reported estimates of the prevalence in the general population ranging from 4 to $23.4 \%$. In the USA it is estimated that as many as $75 \%$ of adults experience some degree of dental fear from mild to severe, and approximately, 5 to $10 \%$ of U.S. adults are considered to experience dental phobia (Kleinknecht et al. 1995, Holtzman et al. 1997).

Dental anxiety can prevent patients from cooperating fully during dental treatment. Given that there is a connection between dental anxiety and uncooperative behavior, it is important for dentists to be able to assess anxiety in their patients. The methods to analyze the objective and subjective scales that are most commonly used to assess the degree of anxiety of children in a dental setting were reviewed by Guinot Jimeno et al. (2011). Phobia of dental care is mostly diagnosed using a fear measurement instrument such as Corah's Dental Anxiety Scale or the Modified Dental Anxiety Scale.

As in other types of stress situations, those involving fear, anxiety or phobia have led researchers to consider the role of hormones, especially those originating from the adrenals. In fact, the role of adrenal hormones in dental fear was already studied in 1954 as an example of stress situations by Hans Selye, the founder of stress theory (Selye 1954).

Anxiety is regarded as a form of stress, and thus has a physiological impact on the body. Stressors can cause the activation of the autonomic nervous system, which prepares the body for the fight-or-flight reaction, and the activation of the hypothalamic-pituitary-adrenal (HPA) axis. The activated autonomic nervous system releases epinephrine and norepinephrine from the adrenal medulla. Norepinephrine has been shown to increase the secretion of salivary alpha amylase (SAA) from the acinar cells of the parotid and submandibular salivary glands. It has been suggested that the level of alpha amylase in the saliva reflects the autonomic nervous system activity, and that measuring it presents an easy, non-invasive measure comparable to measuring the actual catecholamine levels in serum (Dušková et al. 2010). The activity of HPA axis is well reflected by cortisol levels. In plasma, it is standard to measure only total cortisol, which includes both free cortisol and cortisol bound to albumin, corticosteroid-binding globulin and other plasma proteins. Changes in the plasma proteins significantly influence total cortisol levels, so for evaluating the HPA axis measuring free cortisol would be preferable. Free cortisol is possible to measure in the saliva and in the urine. For these reasons, salivary cortisol is a better marker of HPA axis activity (Dušková et al. 2010, Dušková et al. 2016). However, there remains the question of the appropriate cut-off to associate corresponding cortisol levels with a physiological stress reaction or with anxiety or phobia. Otherwise, a physiological stress-induced increase of cortisol cannot be distinguished from a cortisol increase in patients with anxiety or phobias.

The literature on the role of hormones in dental management behavior problems comprises about one hundred papers, which have mainly been focused on the activation of the HPA axis in various situations during dental care. They have generally used salivary cortisol as the marker of the activity of the HPA axis, sometimes simultaneously with salivary alpha amylase, and in several cases this activity was evaluated using the cortisol awakening response (CAR) method (Blomqvist et al. 2007, Kosaka et al. 2014, Barbosa et al. 2012).

\section{The relevance of stress markers for understanding dental management behavior problems}

The stress response to pain or even the anticipation of distress initiates activation of the hypothalamic-pituitary-adrenal axis and causes an increase of cortisol and/or catecholamines. This reaction is a physiological process and can be found in all people, with some rare exceptions. Testing the level of stress hormones in subjects experiencing a toothache or in the dental chair gives us information on the stress reaction, but little about the level of anxiety or whether it is a true phobia. A simple but effective way of evaluating stress in dental patients is with the use of salivary cortisol (Umeanuka et al. 2015). Salivary cortisol levels at various stages of dental treatment in patients with caries were found to be significantly higher in comparison with 
a control group receiving no dental treatment (Kandmir et al. 1977).

In fact, many studies have described associations of the levels of cortisol, alpha amylase and/or epinephrine with the intensity of pain or type of dental care, but several studies failed to show any significant correlation between dental anxiety scores and salivary cortisol and/or alpha amylase levels (Hartung 1976, Hashem et al. 2006, Sadi et al. 2013, Kanegane et al. 2009, Rodrigues Gomes et al. 2013, Patil et al. 2015). However, there are also reports indicating that cortisol levels are indeed associated with dental anxiety (Benjamins et al. 1992, Krueger et al. 2005, Yfanti et al. 2014). Interestingly, some oral diseases inducing stress, such as lichen planus or recurrent aphtous stomatitis, have also been associated with an increase of cortisol levels (McCartan et al. 1996, Koray et al. 2003, Albanidou-Farmaki et al. 2008, Shah et al. 2009, Lopez-Jornet et al. 2016).

Cortisol levels have also been used for evaluations of the intensity of pain and subsequent anxiety during dental care. Cortisol levels are influenced also by the duration and types of treatment. Adrenal stress response associated with tooth extraction(s) is greater than that associated with other routine dental procedures. Cortisol levels at the end of the procedure were elevated by $55 \%$ in groups with prophylaxis and by $48 \%$ in those with extraction compared with baseline cortisol levels (Miller et al. 1995). Several authors have compared patients with anxiety to non-anxious patients according to the Dental Anxiety Scale, showing that anxious patients produced higher levels of cortisol during dental care (Benjamins et al. 1992)

In our opinion, the best way to study patients is to quantify the degree of anxiety independently from the dental care and later compare the stress induced by dental care in anxious and non-anxious patients, similarly as has been done in some studies (Brand 1999, Blomqvist et al. 2007, Barbosa et al. 2012, Kosaka et al. 2014).

Cortisol levels are also influenced by anesthesia. Patients receiving treatment under local anesthesia show lower levels of stress response then those under general anesthesia (Hill and Walker 2001). The efficacy of various sedatives such as midazolam (Jerjes et al. 2005, Isik et al. 2008, Pereira-Santos et al. 2013, Gomez et al. 2015, Shanmugaavel et al. 2016), nitrous oxide, diazepam, cyclooxygenase-2 (COX-2) inhibitors or ineffective melatonin (Seet et al. 2015) have been tested using cortisol levels. Music therapy also has a positive effect in the control of dental anxiety (Mejía-Rubalcava et al. 2015). The perception of pain and dental anxiety can be also altered by the use of oral contraceptives (Rezaii and Ernberg 2010).

Salivary catecholamine levels in children undergoing restorative dental treatment were measured (Mitome et al. 1997) to assess the degree of anxiety during the dental procedures. Salivary norepinephrine significantly increased when the children lay in the dental chair and subsequently received infiltration anesthesia, while salivary epinephrine levels did not significantly change. After treatment, salivary norepinephrine returned to pre-treatment levels. The increase in salivary norepinephrine before infiltration anesthesia likely reflected enhanced peripheral catecholamine release as a result of stress-induced sympathetic responses. However, a principal limitation of that study was the low number of participants.

For better descriptions of dental management behavior problems, additional markers that are also characteristic for other psychic problems might be useful. Bigos et al. (2009) reported 24-h serum dehydroepiandrosterone (DHEA), dehydroepiandrosterone sulphate (DHEA-S), and cortisol concentrations in a young man with obsessive compulsive disorder (OCD) and in 15 healthy young men. Circadian patterns of DHEA and cortisol were markedly different in the subject with OCD than in controls. In addition, DHEA and DHEA-S concentrations were substantially higher in the OCD subject than in the controls, while cortisol levels were similar. Similarly, in our studies of the steroid metabolome in various psychiatric disorders we have found that anxious subjects have significant and typical changes in the levels of some of $\mathrm{C}_{19}$ and $\mathrm{C}_{21}$-steroid metabolites in comparison with controls (Dušková et al. 2016, Hill et al. 2016, Šrámková et al. 2017). Thus, a "dental phobia marker" allowing the discrimination between phobia and stress may be identified in future studies.

\section{Conclusion}

Stress during dental care increases cortisol levels, but these elevated cortisol levels do not inform us to what extent dental management behavior problems contribute to this increase. For a better understanding and description of dental management behavior problems, it will be necessary to include additional markers that are associated with other behavioral disorders. The non-invasive collection of salivary markers will likely be preferable to blood sampling, which itself causes stress 
reactions that can elevate cortisol levels significantly. Changes in neuroactive steroids are characteristic for different neuropsychiatric disorders and could be potential markers allowing discrimination between disorders. However, changes in the cortisol/cortisone ratio may also be necessary to further assess stress reactions. Such a complex view, using changes in both stress and neuroactive hormones, may potentially allow better diagnoses of dental management behavior problems and ameliorate treatment for patients.

\section{Conflict of Interest}

There is no conflict of interest.

\section{Acknowledgements}

The study was supported by the MEYS CR (OP RDE, Excellent research - ENDO.CZ), by $\mathrm{MH} \mathrm{CZ} \mathrm{-} \mathrm{DRO}$ (Institute of Endocrinology - EÚ, 00023761), GACR 14-37368G and PROGRES Q 29/LF1 (Charles University, 1st Faculty of Medicine, Czech Republic).

\section{References}

ALBANIDOU-FARMAKI E, POULOPOULOS AK, EPIVATIANOS A, FARMAKIS K, KARAMOUZIS M, ANTONIADES D: Increased anxiety level and high salivary and serum cortisol concentrations in patients with recurrent aphthous stomatitis. Tohoku J Exp Med 214: 291-296, 2008.

BARBOSA TS, CASTELO PM, LEME MS, GAVIÃO MB: Associations between oral health-related quality of life and emotional statuses in children and preadolescents. Oral Dis 18: 639-647, 2012.

BENJAMINS C, ASSCHEMAN H, SCHUURS AH: Increased salivary cortisol in severe dental anxiety. Psychophysiology 29: 302-305, 1992.

BIGOS KL, FOLAN MM, JONES MR, HAAS GL, KROBOTH FJ, KROBOTH PD: Dysregulation of neurosteroids in obsessive compulsive disorder. J Psychiatr Res 43: 442-445, 2009.

BLOMQVIST M, HOLMBERG K, LINDBLAD F, FERNELL E, EK U, DAHLLÖF G: Salivary cortisol levels and dental anxiety in children with attention deficit hyperactivity disorder. Eur J Oral Sci 115: 1-6, 2007.

BRAND HS: Anxiety and cortisol excretion correlate prior to dental treatment. Int Dent J 49: 330-336, 1999.

DUŠKOVÁ M, SIMU゚NKOVÁ K, HILL M, HRUŠKOVIČOVÁ H, HOSKOVCOVÁ P, KRÁLÍKOVÁ E, STÁRKA L: Higher levels of salivary alpha-amylase predict failure of cessation efforts in male smokers. Physiol Res 59: 765-771, 2010.

DUŠKOVÁ M, HILL M, BIČÍKOVÁ M, ŠRÁMKOVÁ M, ŘÍPOVÁ D, MOHR P, STÁRKA L: The steroid metabolome in men with mood and anxiety disorders. Physiol Res 64 (Suppl 2): S275-S282, 2015.

DUŠKOVÁ M, ŠIMŮNKOVÁ K, VÍTKU゚ J, SOSVOROVÁ L, JANDÍKOVÁ H, POSPÍŠILOVÁ H, ŠRÁMKOVÁ M, KOSÁK M, KRŠEK M, HÁNA V, ŽÁNOVÁ M, SPRINGER D, STÁRKA L: A Comparison of salivary steroid levels during diagnostic tests for adrenal insufficiency. Prague Med Rep 117: 18-33, 2016.

GOMES HS, CORRÊA-FARIA P, SILVA TA, PAIVA SM, COSTA PS, BATISTA AC, COSTA LR: Oral midazolam reduces cortisol levels during local anaesthesia in children: a randomised controlled trial. Braz Oral Res 29: $1-9,2015$.

GUINOT JIMENO F, YUSTE BIELSA S, CUADROS FERNÁNDEZ C, LORENTE RODRÍGUEZ AI, MERCADÉ BELLIDO M: Objective and subjective measures for assessing anxiety in pediatric dental patients. Eur $J$ Paediatr Dent 12: 239-244, 2011.

HARTUNG J: Anxiety and stress in dental practice. 2. Results of studies in children. Stomatol DDR 26: 748-750, 1976.

HASHEM AA, CLAFFEY NM, O'CONNELL B: Pain and anxiety following the placement of dental implants. Int $J$ Oral Maxillofac Implants 21: 943-950, 2006.

HILL CM, WALKER RV: Salivary cortisol determinations and self-rating scales in the assessment of stress in patients undergoing the extraction of wisdom teeth. Br Dent $J$ 191: 513-515, 2001.

HILL M, RIPOVA D, MOHR P, KRATOCHVÍLOVÁ Z, VELIKOVA M, BICIKOVA M, DUSKOVA M, STARKA L: Circulating C19 steroids and progesterone metabolites in women with acute depression and anxiety disorders. Horm Mol Biol Clin Investig 26: 153-164, 2016.

HOLTZMAN JM, BERG RG, MANN J, BERKEY DB: The relationship of age and gender to fear and anxiety in response to dental care. Spec Care Dentist 17: 82-87, 1997. 
ISIK B, BAYGIN O, BODUR H: Premedication with melatonin vs midazolam in anxious children. Paediatr Anaesth 18: 635-641, 2008.

JERJES W, JERJES WK, SWINSON B, KUMAR S, LEESON R, WOOD PJ, KATTAN M, HOPPER C: Midazolam in the reduction of surgical stress: a randomized clinical trial. Oral Surg Oral Med Oral Pathol Oral Radiol Endod 100: 564-570, 2005.

KANDEMIR S, OKŞAN T, ALPÖZ AR, ERGEZER G, KABALAK T: Salivary cortisol levels in children during dental treatment. J Marmara Univ Dent Fac 2: 639-642, 1997.

KANEGANE K, PENHA SS, MUNHOZ CD, ROCHA RG: Dental anxiety and salivary cortisol levels before urgent dental care. J Oral Sci 51: 515-520, 2009

KARJALAINEN S, OLAK J, SÖDERLING E, PIENIHÄKKINEN K, SIMELL O: Frequent exposure to invasive medical care in early childhood and operative dental treatment associated with dental apprehension of children at 9 years of age. Eur J Paediatr Dent 4: 186-190, 2003.

KLEINKNECHT RA, THORNDIKE RM, MCGLYNN FD, HARKAVY J: Factor analysis of the dental fear survey with cross-validation. $J$ Am Dent Assoc 108: 59-61, 1984.

KORAY M, DÜLGER O, AK G, HORASANLI S, UÇOK A, TANYERI H, BADUR S: The evaluation of anxiety and salivary cortisol levels in patients with oral lichen planus. Oral Dis 9: 298-301, 2003.

KOSAKA M, SUMITA YI, OTOMARU T, TANIGUCHI H: Differences of salivary cortisol levels between long-term and short-term wearers of dento-maxillary prosthesis due to head and neck cancer resection. $J$ Prosthodont Res 58: 41-47, 2014.

KRUEGER TH, HELLER HW, HAUFFA BP, HAAKE P, EXTON MS, SCHEDLOWSKI M: The dental anxiety scale and effects of dental fear on salivary cortisol. Percept Mot Skills 100: 109-117, 2005.

LANG PJ, CUTHBERT BN: Affective information processing and the assessment of anxiety. $J$ Behav Assess 6: 369-395, 1984

LOCKER D, LIDDELL A, DEMPSTER L, SHAPIRO D: Age of onset of dental anxiety. J Dent Res 78: 790-796, 1999.

LOPEZ-JORNET P, CAYUELA CA, TVARIJONAVICIUTE A, PARRA-PEREZ F, ESCRIBANO D, CERON J: Oral lichen planus: salival biomarkers cortisol, immunoglobulin A, adiponectin. J Oral Pathol Med 45: 211-217, 2016.

MCCARTAN BE, LAMEY PJ, WALLACE AM: Salivary cortisol and anxiety in recurrent aphthous stomatitis. J Oral Pathol Med 25: 357-359, 1996.

MEJÍA-RUBALCAVA C, ALANÍS-TAVIRA J, MENDIETA-ZERÓN H, SÁNCHEZ-PÉREZ L: Changes induced by music therapy to physiologic parameters in patients with dental anxiety. Complement Ther Clin Pract 21: 282-286, 2015.

MILGROM P, MANCL L, KING B, WEINSTEIN P: Origins of childhood dental fear. Behav Res Ther 33: 313-319, 1995.

MILLER CS, DEMBO JB, FALACE DA, KAPLAN AL: Salivary cortisol response to dental treatment of varying stress. Oral Surg Oral Med Oral Pathol Oral Radiol Endod 79: 436-441, 1995.

MILSOM KM, TICKLE M, HUMPHRIS GM, BLINKHORN AS: The relationship between anxiety and dental experience in 5-year-old children. Br Dent J 9: 503-506, 2003.

MITOME M, SHIRAKAWA T, KIKUIRI T, OGUCHI H: Salivary catecholamine assay for assessing anxiety in pediatric dental patients. J Clin Pediatr Dent 21: 255-259, 1997.

PATIL SJ, SHAH PP, PATIL JA, SHIGLI A, PATIL AT, TAMAGOND SB: Assessment of the changes in the stressrelated salivary cortisol levels to the various dental procedures in children. J Indian Soc Pedod Prev Dent 33: 94-99, 2015.

PEREIRA-SANTOS D, BRÊDA-JÚNIOR MA, FERRAZ EP, CRIPPA GE, DE OLIVEIRA FS, DA ROCHABARROS VM: Study comparing midazolam and nitrous oxide in dental anxiety control. $J$ Craniofac Surg 24: 1636-1639, 2013.

RANTAVUORI K: Aspects and determinants of children's dental fear. University of Oulu, 19-20, 2008. http://jultika.oulu.fi/files/isbn9789514289439.pdf 
REZAII T, ERNBERG M: Influence of oral contraceptives on endogenous pain control in healthy women. Exp Brain Res 203: 329-338, 2010.

RODRIGUES GOMES SS, BARRETOBEZERRA AC, MAIA PRADO AC: Salivary biomarkers, vital signs and behaviour of pre-school children during their first dental visit. Eur J Paediatr Dent 14: 279-283, 2013.

SADI H, FINKELMAN M, ROSENBERG M: Salivary cortisol, salivary alpha amylase, and the dental anxiety scale. Anesth Prog 60: 46-53, 2013.

SEET E, LIAW CM, TAY S, SU C: Melatonin premedication versus placebo in wisdom teeth extraction: a randomised controlled trial. Singapore Med J 56: 666-671, 2015.

SELYE H: The alarm reaction, the general adaptation syndrome, and the role of stress and of the adaptive hormones in dental medicine. Oral Surg Oral Med Oral Pathol 7: 355-367, 1954.

SHAH B, ASHOK L, SUJATHA GP: Evaluation of salivary cortisol and psychological factors in patients with oral lichen planus. Indian J Dent Res 20: 288-292, 2009.

SHANMUGAAVEL AK, ASOKAN S, BABY JJ, PRIYA G, GNANA DEVI J: Comparison of behavior and dental anxiety during intranasal and sublingual midazolam sedation - a randomized controlled trial. $J$ Clin Pediatr Dent 40: 81-87, 2016.

ŠRÁMKOVÁ M, DUŠKOVÁ M, HILL M, BIČÍKOVÁ M, ŘÍPOVÁ D, MOHR P, STÁRKA L: The role of steroids in the prediction of affective disorders in adult men. Steroids 121: 47-53, 2017.

UMEANUKA OT, SAHEEB BD, UGURU CC, CHUKWUNEKE FN: Evaluation of cortisol concentrations in saliva as a measure of stress in patients having routine dental extractions. Br J Oral Maxillofac Surg 53: 557-560, 2015.

YFANTI K, KITRAKI E, EMMANOUIL D, PANDIS N, PAPAGIANNOULIS L: Psychometric and biohormonal indices of dental anxiety in children. A prospective cohort study. Stress 17: 296-304, 2014. 